Article

\title{
Post-Discharge Clostridioides difficile Infection after Arthroplasties in Poland, Infection Prevention and Control as the Key Element of Prevention of $C$. difficile Infections
}

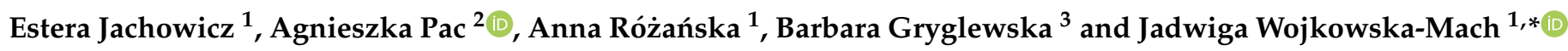 \\ 1 Department of Microbiology, Faculty of Medicine, Medical College, Jagiellonian University, \\ 31-121 Krakow, Poland; estera.jachowicz@doctoral.uj.edu.pl (E.J.); a.rozanska@uj.edu.pl (A.R.) \\ 2 Department of Epidemiology, Medical College, Jagiellonian University, 31-034 Krakow, Poland; \\ agnieszka.pac@uj.edu.pl \\ 3 Department of Internal Medicine and Gerontology, Medical College, Jagiellonian University, \\ 31-501 Krakow, Poland; barbara.gryglewska@uj.edu.pl \\ * Correspondence: mbmach@cyf-kr.edu.pl
}

check for

updates

Citation: Jachowicz, E.; Pac, A.; Różańska, A.; Gryglewska, B.; Wojkowska-Mach, J. Post-Discharge Clostridioides difficile Infection after Arthroplasties in Poland, Infection Prevention and Control as the Key Element of Prevention of $C$. difficile Infections. Int. J. Environ. Res. Public Health 2022, 19, 3155. https:// doi.org/10.3390/ijerph19063155

Academic Editor: Paul B. Tchounwou

Received: 22 January 2022

Accepted: 6 March 2022

Published: 8 March 2022

Publisher's Note: MDPI stays neutral with regard to jurisdictional claims in published maps and institutional affiliations.

Copyright: (C) 2022 by the authors. Licensee MDPI, Basel, Switzerland. This article is an open access article distributed under the terms and conditions of the Creative Commons Attribution (CC BY) license (https:// creativecommons.org/licenses/by/ $4.0 /)$.

\begin{abstract}
Clostridioides difficile is still one of the most common causes of hospital-acquired infectious diarrhea (CDI), and the incidence of CDI is one of the indicators that allows conclusions to be derived on the correctness of antibiotic administration. The objective of this observational study was the analysis of post-discharge CDI incidence in patients undergoing hip or knee arthroplasty, in order to specify optimum conditions for the surgical procedures and outpatient postoperative care. Oneyear observational study. Public Polish hospitals. Retrospective records for 83,525 surgery patients having undergone hip or knee arthroplasty were extracted from the Polish National Health Fund databases. CDI and/or antibiotic prescriptions in the 30 day post-surgery period were expressed per 1000 surgeries with antibiotic prescription on discharge or in ambulatory care, respectively. The CDI incidence rate was 34.4 per 10,000 patients, and 7.7 cases per 100,000 post-surgery patient-days. Patients who were prescribed at least one antibiotic were diagnosed with CDI more often than patients who had no antibiotic treatment (55.0/1000 patients vs. 1.8/1000 patients). In the multifactorial analysis, the following factors were significant: being at least 65 years of age, trauma as the cause of surgery, length of stay over 7 days, HAIs other than CDI and taking beta-lactams and/or quinolones but not macrolides in the post-discharge period. Postoperative antibiotic prescription in patients undergoing joint replacement surgery is the main risk factor for CDI. These observations indicate the necessity of improvement of infection control programs as the key factor for CDI prevention.
\end{abstract}

Keywords: Clostridioides difficile; post-discharge surveillance; hip and knee arthroplasties; healthcareassociated CDI

\section{Introduction}

Clostridioides difficile is the most frequent cause of nosocomial diarrhea syndrome with possible severe progression. Recurrence of the disease is associated with higher health system costs, as well as exposing patients to additional health risks [1]. CDI (Clostridioides difficile infection) is usually associated with healthcare; however, the number of community-acquired infections is on the rise. CDIs are most frequently related to changes in the gut microbiota caused by the administration of antibiotics, and patients who are elderly, immunocompromised or have undergone surgery are at a greater risk of developing CDI and recurrent infection [2].

Healthcare-associated infections, considered as some of the most important public health problems, can be effectively prevented by implementing evidence-based methods of infection prevention and control. Effective implementation also involves monitoring of process and outcomes indicators. The incidence of CDI is one of the indicators that 
allows conclusions to be derived about the correctness of antibiotic administration, which is also closely related to the prevention of infections. In Poland, there is no network of infection surveillance that would bring together many centers, and research in the area of epidemiology of infections is carried out primarily in single centers. As a result, there are deficiencies in the practice of infection control, e.g., no post-discharge registration, ineffective cooperation between clinicians and microbiological laboratories [3,4] or suboptimal use of antibiotics [5]. According to the European Centre for Disease Prevention and Control (ECDC), the CDI incidence in Poland is almost three times higher than the EU average [6]. In their previous work, the authors have noted the correlations between antibiotic prophylaxis in urology and CDI [5]. The aim of this study is to find out whether similar correlations can be observed in orthopedics.

Data covering large groups of patients include, for example, registers and databases of the public payer for health services in Poland. Analyses of data from the Polish National Health Fund (NHF) databases, taking into account specific groups of patients or areas of public health, may constitute a valuable supplement to the results from single-center studies. The research question of our observational, non-interventional study was: what is the incidence of post-discharge CDI and how is it associated with different risk factors in adult surgery patients following hip and knee arthroplasties, compared to patients without a CDI diagnosis in the 30 days following the surgery?

\section{Materials and Methods}

Retrospective records for all patients who underwent hip or knee arthroplasties in 2017 were extracted from the Polish NHF (the only public payer in Poland) databases. The data include only procedures performed within the general health care system. The current analysis employs data on adults who underwent hip or knee prosthesis surgery, identified on the basis of the following ICD-9 codes: $81.51-81.55,00.7$ or 00.8 . We excluded surgeries performed in people under 18 years old $(n=58)$. In total, 83,525 cases of hip (HPRO) and knee (KPRO) arthroplasties were included in the present analysis. The inclusion criteria were (1) hip or knee prosthesis reimbursed by the NHF and performed between 1 January 2017 and 31 December 2017, and (2) patient age (18 or more years old). The studied population has previously been described in detail [7].

We used the NHF data on the 192 CDI observed in the 30 day post-discharge period (hospitalizations, outpatient visits, etc.). We analyzed the demographic (age, place of residence) and clinical (chronic comorbidities, operated joint: hip/knee) characteristics of the patients, the number of drug groups prescribed, whether it was a primary or revision surgery according to the appropriate ICD-9 code, length of hospital stay (LOS), whether there was a stay in the intensive care unit (ICU), cause of surgery, postoperative infections, primary/revision surgery, as well as the long-term care after surgery. Patients with these particular disease entities at the preoperative stage were assessed based on the use of specific drug groups during a period of one year before the date of the procedure. The criterion for polytherapy was taking drugs from 5 or more ATC-code groups. Only prescribed drugs were taken into consideration.

HCA-CDI were diagnosed (with or without microbiological confirmation) and classified based on the uniform definitions issued by the ECDC, in accordance with the decision of the European Commission 2002/253/EC laying down case definitions for reporting communicable diseases to the community network [8]. According to the ECDC, the origin of a CDI case can be defined as healthcare-associated (HCA-CDI) based on the date (within 30 days of discharge from a healthcare facility) and location of the onset of CDI symptoms [9]. A 30 day time span was also employed in relation to post-discharge antibiotic prescription. The sensitivity of post-discharge CDI surveillance and postoperative follow-up of patients was dependent on the primary care physician and the relationship between inpatient and outpatient ABX treatment is unknown. 
The post-surgery patient-days were calculated as follows: the number of days between the operation day and the day of the outpatient visit due to CDI or hospitalization due to CDI during the 30 day post-operation period.

Antibiotic prescriptions were expressed per 1000 surgery patients with an antibiotic prescription on discharge from hospital, or in ambulatory care, respectively in the 30 day post-surgery period using the ATC (Anatomical Therapeutic Chemical) system of the World Health Organization [10]. Only antibiotics for systemic use were taken into account-no antifungal (J02), antimycobacterial (J04), or antiviral (J05) drugs were included in the analyses. Combination antibiotic therapy was defined as the prescription of two or more different antibiotics.

This work was approved by the Bioethics Committee of Jagiellonian University (approval no.1072.6120.149.2020). The study was based on data gathered during routine patient care and the analysis did not include any individual participant's data.

\section{Statistical Analysis}

The incidence of CDI (per 1000 patients) was calculated along with exact binomial $95 \%$ confidence intervals $(95 \% \mathrm{CI})$, and compared in relation to demographic characteristics, and the description of the hospitalization index (due to knee or hip arthroplasty), as well as antibiotic prescriptions in post-hospital period by a Chi-squared test. In addition, multivariable logistic regression was applied to assess the strength of association between CDI and the chosen risk factors. The independent variables were chosen based on both (a) the significance of difference in CDI incidence, and (b) factors that can be related to CDI incidence based on literature searching and experience. The results are presented as odds ratios (OR), together with 95\% confidence intervals (95\% CI). Results with a $p$-value $<0.05$ were considered statistically significant. All analyses were performed in IBM SPSS Statistics 26 (PS IMAGO PRO, Predictive Solutions Sp. z o.o.).

\section{Results}

In total, there were 192 CDIs, including 160 cases after HPRO (0.3/1000 patients) and 32 after $\mathrm{KPRO}$ (0.1/1000 patients). The CDI incidence rate was 34.4 per 10,000 patients, and 7.7 cases per 100,000 post-surgery patient-days (pds).

Patients who required Combination ABX therapy in the postoperative period suffered from CDIs significantly more often than patients who did not undergo such therapy, as follows: 2.8/1000 patients vs. 1.8/1000 patients (Table 1). A similar result was found in patients operated on due to trauma, in whom 7.9/1000 patients experienced CDIs, compared with those operated on due to degeneration (1.2/1000 patients) or complication (3.2/1000 patients); most often, CDI concerned a small group of patients not qualified elsewhere (reason: others, 6.7/1000 patients). However, in patients admitted in an emergency, post-discharge CDI was diagnosed significantly more often (4.6/1000 patients) than in patients admitted for scheduled procedures (1.7/1000 patients) (Table 1$)$.

Table 1. Clostridioides difficile infection incidence in relation to patient and operation characteristics.

\begin{tabular}{|c|c|c|c|c|c|}
\hline Characteristics of & Study Group & $\begin{array}{c}\text { Total, } \\
\mathrm{N}=83,525\end{array}$ & $\begin{array}{c}\text { No. of CDI } \\
\text { Cases }\end{array}$ & $\begin{array}{c}\text { Incidence } \\
\text { (95\% CI) Per } \\
1000 \text { Patients }\end{array}$ & $p$-Value \\
\hline \multirow{2}{*}{ Sex } & Female & 52,624 & 129 & $2.5(2.0-2.9)$ & \multirow{2}{*}{0.229} \\
\hline & Male & 30,901 & 63 & $2.0(1.6-2.6)$ & \\
\hline \multirow{2}{*}{ Age } & $<65$ & 27,855 & 28 & $1.0(0.7-1.5)$ & \multirow{2}{*}{$<0.001$} \\
\hline & $>=65$ years & 55,670 & 164 & $2.9(2.5-3.4)$ & \\
\hline \multirow{2}{*}{$\begin{array}{c}\text { Place of } \\
\text { residence-city * }\end{array}$} & Yes & 48,583 & 111 & $2.3(1.8-2.9)$ & \multirow{2}{*}{0.944} \\
\hline & No & 34,657 & 80 & $2.3(1.9-2.8)$ & \\
\hline
\end{tabular}


Table 1. Cont.

\begin{tabular}{|c|c|c|c|c|c|}
\hline Characteristics of $t$ & Study Group & $\begin{array}{c}\text { Total, } \\
\mathrm{N}=83,525\end{array}$ & $\begin{array}{l}\text { No. of CDI } \\
\text { Cases }\end{array}$ & $\begin{array}{c}\text { Incidence } \\
\text { (95\% CI) Per } \\
1000 \text { Patients }\end{array}$ & $p$-Value \\
\hline \multirow{2}{*}{ Admission mode } & Scheduled & 66,222 & 112 & $1.2(0.9-1.5)$ & \multirow{2}{*}{$<0.001$} \\
\hline & Emergency & 17,149 & 79 & $6.5(5.4-7.9)$ & \\
\hline \multirow{4}{*}{ Cause of surgery } & Degeneration & 66,227 & 79 & $1.2(0.9-1.5)$ & \multirow{4}{*}{$<0.001$} \\
\hline & Injury & 11,967 & 94 & $7.9(6.4-9.6)$ & \\
\hline & Complications & 4736 & 15 & $3.2(1.8-5.2)$ & \\
\hline & Other & 595 & 4 & $6.7(1.8-17.1)$ & \\
\hline \multirow{2}{*}{ Joint operated on } & Hip & 56,068 & 160 & $2.9(2.4-3.3)$ & \multirow{2}{*}{$<0.001$} \\
\hline & Knee & 27,457 & 32 & $1.2(0.8-1.6)$ & \\
\hline \multirow{2}{*}{ Surgery } & Primary & 78,388 & 175 & $2.2(1.9-2.6)$ & \multirow{2}{*}{0.119} \\
\hline & Revision & 5137 & 17 & $3.3(1.9-5.3)$ & \\
\hline \multirow{2}{*}{$\begin{array}{l}\text { ICU during the 1st } \\
\text { hospitalization }\end{array}$} & No & 83,056 & 171 & $2.1(1.8-2.4)$ & \multirow{2}{*}{$<0.001$} \\
\hline & Yes & 469 & 21 & $44.8(27.9-67.6)$ & \\
\hline \multirow{2}{*}{$\begin{array}{c}\text { Prolonged } \\
\text { hospitalization * }\end{array}$} & No & 66,009 & 119 & $1.8(1.5-2.2)$ & \multirow{2}{*}{$<0.001$} \\
\hline & Yes & 17,501 & 72 & $4.1(3.2-5.2)$ & \\
\hline \multirow{2}{*}{$\mathrm{ABX}$ s on discharge } & No & 79,994 & 181 & $2.3(1.9-2.6)$ & \multirow{2}{*}{0.301} \\
\hline & Yes & 3531 & 11 & $3.1(1.6-5.6)$ & \\
\hline \multirow{2}{*}{$\begin{array}{c}\text { Combination ABX } \\
\text { therapy }\end{array}$} & No & 40,214 & 71 & $1.8(1.4-2.2)$ & \multirow{2}{*}{0.002} \\
\hline & Yes & 43,311 & 121 & $2.8(2.3-3.3)$ & \\
\hline \multirow{2}{*}{$\begin{array}{c}\text { Long-term } \\
\text { postoperative care }\end{array}$} & No & 82,818 & 181 & $2.2(1.9-2.5)$ & \multirow{2}{*}{$<0.001$} \\
\hline & Yes & 707 & 11 & $15.6(7.8-27.7)$ & \\
\hline
\end{tabular}

The median stay in hospital for CDI cases was 7 days. This result is in the third quartile of patients without CDI. Significantly more often, CDI occurred in patients from a small group requiring hospitalization in the ICU, as follows: 44.8/1000 patients vs. 2.1/1000 patients among non-ICU patients (Table 1). Also, patients who required longterm care after discharge were infected more often than patients who did not receive such care, as follows: $15.6 / 1000$ vs. $2.2 / 1000$ patients (Table 1 ).

A total of 3531 people received a prescription of antibiotics on discharge. The incidence in this group was 3.1/1000 patients and was not significantly higher than for the patients who were not prescribed an antibiotic $(2.3 / 1000)$ (Table 1$)$.

Significantly more frequently, CDI occurred in patients with other healthcare-associated infections in the post-discharge period; the incidence rate in this group was $27 / 1000$ patients. Of all studied surgical patients, 763 were prescribed at least one antibiotic in outpatient care in the 30 day postoperative period (Table 2), and in these patients, more often than in patients without antibiotic treatment, CDI was diagnosed (55.0/1000 patients vs. $1.8 / 1000$ patients) (Table 2).The incidence of CDI increased with the number of prescriptions filled; the incidence with one prescription was 53.9/1000 patients, and with more than one prescription, $57.8 / 1000$ patients (Table 2).

The incidence of post-discharge CDI associated with antibiotic treatment was significantly dependent on the class of the antibiotic; the highest incidence was associated with other beta-lactams (97.0/1000 patients), beta-lactams, penicillins (58.8/1000 patients) and quinolones (45.5/1000 patients) (Table 2). 
Table 2. Antibiotic prescriptions in the post-discharge period in ambulatory care.

\begin{tabular}{|c|c|c|c|c|c|}
\hline \multicolumn{2}{|c|}{$\begin{array}{l}\text { Characteristics of the } \\
\text { Study Group }\end{array}$} & \multirow{2}{*}{$\begin{array}{c}\begin{array}{c}\text { Total, } \\
\mathbf{N}=\mathbf{8 3 , 5 2 5}\end{array} \\
82,762\end{array}$} & \multirow{2}{*}{$\begin{array}{c}\begin{array}{c}\text { Number } \\
\text { of Cases }\end{array} \\
150\end{array}$} & \multirow{2}{*}{$\begin{array}{c}\begin{array}{c}\text { Incidence }(\mathbf{9 5} \% \mathrm{CI}) \\
\text { Per } \mathbf{1 0 0 0} \text { Patients }\end{array} \\
1.8(1.5-2.1)\end{array}$} & \multirow[t]{2}{*}{$p$-Value } \\
\hline \multirow{2}{*}{$\mathrm{ABX}$ prescriptions } & No & & & & \\
\hline & Yes & 763 & 42 & $55.0(40.0-73.7)$ & \\
\hline \multirow{2}{*}{ Non-CDI HAI } & No & 81,765 & 144 & $1.8(1.5-2.1)$ & \multirow{2}{*}{$<0.001$} \\
\hline & Yes & 1760 & 48 & $27.3(20.2-36.0)$ & \\
\hline \multirow{3}{*}{$\begin{array}{l}\text { Number of } A B X \\
\text { prescriptions }\end{array}$} & No & 82,762 & 150 & $1.8(1.5-2.1)$ & \multirow{3}{*}{$<0.001$} \\
\hline & 1 & 538 & 29 & $53.9(36.4-76.5)$ & \\
\hline & $>1$ & 225 & 13 & $57.8(31.1-96.8)$ & \\
\hline \multirow{2}{*}{$\begin{array}{l}\text { J01C, beta-lactams, } \\
\text { penicillins }\end{array}$} & No & 83,320 & 180 & $2.2(1.9-2.5)$ & \multirow{2}{*}{$<0.001$} \\
\hline & Yes & 205 & 12 & $58.5(30.6-100.0)$ & \\
\hline \multirow{2}{*}{$\begin{array}{l}\text { J01D, other } \\
\text { beta-lactams }\end{array}$} & No & 83,391 & 179 & $2.1(1.8-2.5)$ & \multirow{2}{*}{$<0.001$} \\
\hline & Yes & 134 & 13 & $97(52.7-160.2)$ & \\
\hline \multirow{2}{*}{ J01F, macrolides } & No & 83,424 & 188 & $2.3(1.9-2.6)$ & \multirow{2}{*}{$<0.001$} \\
\hline & Yes & 101 & 4 & $39.6(10.9-98.3)$ & \\
\hline \multirow{2}{*}{ J01M, quinolones } & No & 83,217 & 178 & $2.1(1.8-2.5)$ & \multirow{2}{*}{$<0.001$} \\
\hline & Yes & 308 & 14 & $45.5(25.1-75.1)$ & \\
\hline \multirow{2}{*}{ J01, others } & No & 83,365 & 184 & $2.2(1.9-2.5)$ & \multirow{2}{*}{$<0.001$} \\
\hline & Yes & 160 & 8 & $50(21.8-96.1)$ & \\
\hline
\end{tabular}

* no data for 15 patients, ABX-antibiotic, CDI-Clostridioides difficile infections, HAI-healthcare associated infections. J01, others antibacterial for systematic use.

In the multifactorial analysis, the following factors were found to be significant: age over 65 years of age, stay in the intensive care unit, trauma as the cause of surgery, length of stay over 7 days, HAIs other than CDI and taking beta-lactams and other beta-lactams and/or quinolones J01M, but not macrolides, in the post-discharge period (Table 3).

Table 3. Multivariable analysis of the influence of the studied factors on the incidence of CDI.

\begin{tabular}{cccc}
\hline Study Group & OR & $\mathbf{9 5 \% C I}$ & $p$ \\
\hline Man & 0.98 & $0.71-1.34$ & 0.901 \\
\hline Age $>$ 65 years & 1.78 & $1.16-2.73$ & 0.008 \\
\hline multimorbidity & 1.05 & $0.72-1.55$ & 0.791 \\
\hline J01C, beta-lactams, penicillins & 4.18 & $2.04-8.57$ & $<0.001$ \\
\hline J01D, other beta-lactams & 6.41 & $3.15-13.02$ & $<0.001$ \\
\hline J01F, macrolides & 2.69 & $0.88-8.24$ & 0.084 \\
\hline J01M, quinolones & 2.80 & $1.42-5.54$ & 0.003 \\
\hline J01, other antibacterial for systematic use & 3.17 & $1.39-7.25$ & 0.006 \\
\hline Long-term care after discharge & 2.55 & $1.32-4.93$ & 0.005 \\
\hline Knee surgery & 0.82 & $0.53-1.27$ & 0.374 \\
\hline ICU & 13.17 & $7.95-21.81$ & $<0.001$ \\
\hline Revision & 0.85 & $0.23-3.14$ & 0.810 \\
\hline HAI (not with C. difficile) & 3.58 & $2.15-5.94$ & $<0.001$ \\
\hline Cause of surgery, degeneration (ref.) & & Ref & \\
\hline
\end{tabular}


Table 3. Cont.

\begin{tabular}{cccc}
\hline Study Group & OR & $\mathbf{9 5 \% C I}$ & $p$ \\
\hline other & 2.53 & $0.77-8.35$ & 0.128 \\
\hline complications & 1.71 & $0.43-6.89$ & 0.448 \\
\hline injury & 3.44 & $2.37-4.98$ & $<0.001$ \\
\hline Hospitalization for more than 7 days & 1.62 & $1.19-2.2$ & 0.002
\end{tabular}

OR-odds ratio, 95\%CI-95\% confidence interval, $p$-probability value, ICU—intensive care unit, HAI-healthcare associated infections.

\section{Discussion}

This study demonstrates that the risk of the occurrence of CDI is closely associated with both factors independent of the course of medical care, such as age or need for surgery due to an injury, and factors directly related to the healthcare system, such as the need to treat HAIs or the use of antibiotics in such patients.

The fact that the risk of CDI increases with age and with deteriorating general condition, when patients require long-term care, has been confirmed by other authors [11,12]. Antimicrobials are some of the most commonly prescribed medications in long-term care settings. Therefore, it is not surprising that Clostridium difficile associated diarrhea is common in older residents. CDI has been identified as the most frequent cause of non-epidemic acute diarrhea in long-term care facilities (LTCF) [13]. In our study, people over the age of 65 were diagnosed with CDI three times more often than younger people, and patients requiring long-term care following surgery were eight times more prone to it than people who did not require such care. Additionally, people who underwent combination antibiotic therapy suffered from CDI twice as often than patients who did not undergo polytherapy. Patients who requires constant care often suffer from many diseases and usually have a weakened immune system, altered gut microbiota or other related severe pathologies. The study by Donskey et al. suggests that asymptomatic carriage and CDI among the LTCF residents contribute to the transmission of $C$. difficile in both LTCF and in hospital during admissions to the unit. There is a need for greater emphasis on infection control measures and the management of antimicrobial drugs in LTCF [14].

A study by Weber et al. demonstrated that antibiotics are prescribed more often to LTCF patients, which may be associated with an increased risk of poor outcomes in the post-discharge period [15]. Also, insufficient post-discharge care caused by poor communication with patients and/or improper conveying of information between hospital medical staff and caregivers may result in an increased probability of adverse events and pre-hospitalization [16].

Perioperative proceedings, especially a prolonged stay and the need for an ICU stay, were found to be of great significance. The percentage of people with CDI increased with prolonged hospital stays; similar results were obtained by Hung et al. [17]. CDI is one of the most important causes of hospital-acquired infections in intensive care units (ICU) [18], which may be related to the amount of antibiotics prescribed there; approximately $70 \%$ of ICU patients are prescribed antibiotics [19]. Also, increasing duration of antimicrobial prophylaxis is associated with higher odds of CDI. These findings highlight the idea that stewardship efforts to limit the duration of prophylaxis have the potential to reduce adverse events without increasing SSI [20]. A similar phenomenon has been observed by the authors with regard to another patient population, i.e., subjects requiring urogenital procedures, in which, on the basis of regression coefficients, a positive correlation was demonstrated between the use of fluoroquinolones and the HA-CDI incidence rate [5].

The relationship between the class of antibiotics prescribed and the incidence of CDI has been debated for several years. The antibiotics associated with the highest risk of developing CDI include the following: clindamycin, fluoroquinolones, cephalosporins, and carbapenems [21]. Knecht et al. showed that different antibiotic classes (cephalosporins, ampicillin/sulbactam and quinolones) affect the gut microbiota similarly at the RNA level 
but differently at the DNA level, and this explains why several different antibiotics are associated with similar intestinal problems [22].

However, a significant outcome of our study was the fact that the need for antibiotic treatment of infections is a significant risk of CDI, as well as the occurrence of another infection.

This observation has practical implications for infection prevention and control in Poland and is consistent with the results of other studies in which higher rates of incidence of surgical site infections were observed following operations associated with implantation of both knee and hip joints. Ziółkowski et al. found incidences of SSIs after hip and knee arthroplasty surgeries of $5.8 \%$ and $5.4 \%$, respectively (2013-2015), while the average rates reported in the HAI-Net SSI ECDC program for 2015 were $1.1 \%$ and $0.6 \%$, respectively [23,24].

Observation of risk factors for infection has been carried out in over 39,000 patients undergoing primary hip or knee arthroplasty; the data came from a large database of the American College of Surgeons National Surgical Quality Improvement Program [25]. In this study, the frequency of CDI incidents in the 30 day postoperative period was $0.10 \%$ $(95 \%$ CI, $0.07-0.13 \%)$. The independent preoperative and procedural risk factors were older age, functional dependence, preoperative anemia, hypertension, and hip arthroplasty. Postoperative risk factors included urinary tract infection, sepsis, and the development of any infection.

For many years, a relationship has been known to exist between a reduction in gastric acidity and the risk of Clostridioides difficile infection and the development of pseudomembranous enterocolitis, especially with concurrent antibiotic therapy. This relationship is visible with histamine 2 receptor antagonist treatment, but with proton pump inhibitors (PPIs), this association is much greater [26]. A meta-analysis of 23 studies involving approximately 300,000 patients demonstrated that PPI treatment increases the risk of developing this infection by nearly $65 \%$ [27]. Modification of the gut microbiota composition, associated with PPI treatment, also promotes the development of small intestinal bacterial overgrowth syndrome (SIBO). A meta-analysis of 19 studies encompassing over 7000 patients found that this risk grows by around 70\% [28]. Of other drugs of potential relevance to CDI infection, a meta-analysis by Furuya-Kanamori et al. demonstrated the importance of exposure to corticosteroids [29]. Unfortunately, the methodology of our study makes it impossible to verify the importance of the application of particular groups of drugs for the occurrence of CDI.

Our results have several important implications for clinical practice in Poland, especially for the area of infection control. Multimorbidity in the preoperative period and beta-lactams or quinolones prescription within 30 days of discharge from hospitals are associated with increased CDI rates. Thus, our observation confirms the necessity of implementing effective antimicrobial stewardship programs in Polish hospitals, as well as continuous education for physicians working in the community sector, since according to several recent studies on antimicrobial consumption in Poland this is not optimal [30]. Additionally, another HAI-other than CDI-in the post-discharge period is associated with a higher risk of CDI, which is directly related to the ineffectiveness of infection control programs, lack of post-discharge surveillance in surgical patients, or difficulties with access to proper microbiological diagnostics in Polish hospitals. We have also shown that a stay in long-term care facilities after discharge is associated with higher CDI incidence, and the HALT-3 project revealed problems with infection control and antibiotic consumption in these settings in Poland [31].

The use of fluoroquinolones, due to their numerous side effects, should be limited to situations where there are no other therapeutic options available. Furthermore, according to a European Medicines Agency alert from 2018, in the elderly, quinolones should be used with special caution [32]. At present in Poland, quinolones are prescribed most frequently; they make up more than $40 \%$ of all antibiotic prescriptions. Unfortunately, there are concerns regarding the growth of fluoroquinolone prescriptions in Poland in recent years, as a percentage of the total antibiotic consumption [31]. 
There are also limitations to the presented results. Firstly, this was an observational study. The reason for prescribing antibiotics is unknown, as the available data relates only to the sale of drugs, not the consumption. Secondly, the level of CDI diagnostics is unknown (only clinical signs or performed diagnostic tests and their type). The role of proton pump inhibitors in the risk of CDI has not been analyzed, and information about perioperative antibiotic prophylaxis and its duration are unknown. In addition, the source of the data also makes it impossible to determine whether post-surgery inpatient and outpatient antibiotics were prescribed only for patients with confirmed infections. However, the value of our analysis is its pioneering nature, and the results indicate areas of surgical care that require more thorough research and intervention.

\section{Conclusions}

In Poland the CDI incidence rate is 34.4 cases per 10,000 patients, and 7.7 per 100,000 postsurgery pds. Multivariable analysis of risk factors for CDI up to 30 days after hospitalization shows that various factors influence the risk of developing CDI; among these factors are another healthcare-associated infection in the post-discharge period and antibiotic prescription within 30 days of discharge. These observations, together with the results of other studies in this area in Poland, indicate the necessity of improvement of infection control programs as the key factor for prevention of $C$. difficile, as well as continuous education for physicians working mainly in ambulatory care and the community.

Author Contributions: Conceptualization, E.J., A.R., B.G. and J.W.-M.; Data curation, E.J., A.P. and J.W.-M.; Formal analysis, E.J., A.P. and J.W.-M.; Funding acquisition, J.W.-M.; Investigation, E.J.; Methodology, E.J.; Software, A.P.; Supervision, J.W.-M.; Writing-original draft, E.J., A.R., B.G. and J.W.-M.; Writing-review and editing, E.J., A.P. and J.W.-M. All authors have read and agreed to the published version of the manuscript.

Funding: The research project was conducted under the supervision of Jadwiga Wojkowska-Mach. Research was supported by a grant from the Jagiellonian University Medical College N41/DBS/000704. This study was carried out as part of our routine work.

Institutional Review Board Statement: The study was conducted according to the guidelines of the Declaration of Helsinki, and approved by the Bioethics Committee of Jagiellonian University, Krakow (approval no. 1072.6120.149.2020). The study was based on data gathered during routine patient care and the analysis did not include any individual participant's data.

Informed Consent Statement: Not applicable.

Data Availability Statement: The datasets during and/or analysed during the current study available from Estera Jachowicz (e-mail: estera.jachowicz@doctoral.uj.edu.pl) on reasonable request.

Acknowledgments: We would like to thank Dominik Żabiński from the Department of Analyses and Innovation of the Polish National Health Fund.

Conflicts of Interest: The authors have no conflict of interest to disclose. The manuscript has been read and approved by all the authors.

\section{References}

1. Petrosillo, N.; Granata, G.; Cataldo, M.A. Novel Antimicrobials for the Treatment of Clostridium difficile Infection. Front. Med. 2018, 5, 96. [CrossRef]

2. Oksi, J.; Anttila, V.J.; Mattila, E. Treatment of Clostridioides (Clostridium) difficile infection. Ann. Med. 2020, 5, 12-20. [CrossRef]

3. Różańska, A.; Jarynowski, A.; Kopeć-Godlewska, K.; Wójkowska-Mach, J.; Misiewska-Kaczur, A.; Lech, M.; Rozwadowska, M.; Karwacka, M.; Liberda, J.; Domańska, J. Does surgical site infection after Caesarean section in Polish hospitals reflect high-quality patient care or poor postdischarge surveillance? Results from a 3-year multicenter study. Am. J. Infect. Control. 2018, 46, 20-25. [CrossRef]

4. Dubiel, G.; Rogoziński, P.; Żaloudik, E.; Bruliński, K.; Różańska, A.; Wojkowska-Mach, J. Identifying the Infection Control Areas Requiring Modifications in Thoracic Surgery Units: Results of a Two-Year Surveillance of Surgical Site Infections in Hospitals in Southern Poland. Surg. Infect. 2017, 18, 820-826. [CrossRef] [PubMed] 
5. Jachowicz, E.; Wałaszek, M.; Sulimka, G.; Maciejczak, A.; Zieńczuk, W.; Kołodziej, D.; Karaś, J.; Pobiega, M.; Wójkowska-Mach, J. Long-Term Antibiotic Prophylaxis in Urology and High Incidence of Clostridioides difficile Infections in Surgical Adult Patients. Microorganisms 2020, 8, 810. [CrossRef]

6. European Centre for Disease Prevention and Control. Healthcare-associated infections: Clostridium difficile infections. In Annual Epidemiological Report for 2016; ECDC: Stockholm, Sweden, 2018.

7. Gajda, M.; Pac, A.; Gryglewska, B.; Gajda, P.; Różańska, A.; Wójkowska-Mach, J. Patients Undergoing Hip or Knee Arthroplasty in Poland Based on National Data-Challenge for Healthcare in Aging Society. Healthcare 2021, 9, 924. [CrossRef]

8. 2012/506/EU: Commission Implementing Decision of 8 August 2012 Amending Decision 2002/253/EC Laying Down Case Definitions for Reporting Communicable Diseases to the Community Network under Decision No 2119/98/EC of the European Parliament and of the Council (Notified under Document C (2012) 5538) Text with EEA Relevance. Published 2012. Available online: https: / / eur-lex.europa.eu/LexUriServ/LexUriServ.do?uri=OJ:L:2012:262:0001:0057:EN:PDF (accessed on 1 October 2021).

9. European Centre for Disease Prevention and Control. European Surveillance of Clostridium Difficile Infection; Surveillance protocol version 2.3; ECDC: Stockholm, Sweden, 2017.

10. WHO Collaborating Centre for Drug Statistics Methodology. Guidelines for ATC Classification and DDD Assignment 2013; WHO: Oslo, Norway, 2012.

11. Negrut, N.; Bungau, S.; Behl, T.; Khan, S.; Vesa, C.; Bustea, C.; Nistor-Cseppento, D.; Rus, M.; Pavel, F.-M.; Tit, D. Risk Factors Associated with Recurrent Clostridioides difficile Infection. Healthcare 2020, 8, 352. [CrossRef] [PubMed]

12. Negrut, N.; Nistor-Cseppento, D.C.; Khan, S.A.; Pantis, C.; Maghiar, T.A.; Maghiar, O.; Aleya, S.; Rus, M.; Tit, D.M.; Aleya, L.; et al. Clostridium difficile Infection Epidemiology over a Period of 8 Years-A Single Centre Study. Sustainability 2020, $12,4439$. [CrossRef]

13. Simor, A.E.; Bradley, S.F.; Strausbaugh, L.J.; Crossley, K.; Nicolle, L.E. Long-Term-Care Committee. Clostridium difficile in long-term-care facilities for the elderly. Infect. Control Hosp. Epidemiol. 2002, 23, 696-703. [CrossRef]

14. Donskey, C.J.; Sunkesula, V.C.K.; Stone, N.D.; Gould, C.V.; McDonald, L.C.; Samore, M.; Mayer, J.; Pacheco, S.M.; Jencson, A.L.; Sambol, S.P.; et al. Transmission of Clostridium difficile from asymptomatically colonized or infected long-term care facility residents. Infect. Control Hosp. Epidemiol. 2018, 39, 909-916. [CrossRef] [PubMed]

15. Weber, B.R.; Noble, B.N.; Bearden, D.T.; Crnich, C.J.; Ellingson, K.D.; McGregor, J.C.; Furuno, J.P. Antibiotic prescribing upon discharge from the hospital to long-term care facilities: Implications for antimicrobial stewardship requirements in post-acute settings. Infect. Control Hosp. Epidemiol. 2019, 40, 18-23. [CrossRef]

16. Backman, C.; Chartrand, J.; Dingwall, O.; Shea, B. Effectiveness of person- and family-centered care transition interventions: A systematic review protocol. Syst. Rev. 2017, 6, 158. [CrossRef]

17. Hung, Y.-P.; Lee, J.-C.; Lin, H.-J.; Liu, H.-C.; Wu, Y.-H.; Tsai, P.-J.; Ko, W.-C. Clinical impact of Clostridium difficile colonization. Microbiol. Immunol. Infect. 2015, 48, 241-248. [CrossRef]

18. Zahar, J.-R.; Schwebel, C.; Adrie, C.; Garrouste-Orgeas, M.; Français, A.; Vesin, A.; Nguile-Makao, M.; Tabah, A.; Laupland, K.; Le-Monnier, A.; et al. Outcome of ICU patients with Clostridium difficile infection. Crit. Care 2012, 16, 215. [CrossRef]

19. Wischmeyer, P.E.; McDonald, D.; Knight, R. Role of the microbiome, probiotics, and 'dysbiosis therapy' in critical illness. Curr. Opin. Crit. Care 2016, 22, 347. [CrossRef]

20. Branch-Elliman, W.; O’Brien, W.; Strymish, J.; Itani, K.; Wyatt, C.; Gupta, K. Association of Duration and Type of Surgical Prophylaxis With Antimicrobial-Associated Adverse Events. JAMA Surg. 2019, 154, 590-598. [CrossRef]

21. Deshpande, A.; Pasupuleti, V.; Thota, P.; Pant, C.; Rolston, D.D.K.; Sferra, T.J.; Hernandez, A.V.; Donskey, C.J. Communityassociated Clostridium difficile infection and antibiotics: A meta-analysis. J. Antimicrob. Chemother. 2013, 68, 1951-1961. [CrossRef] [PubMed]

22. Knecht, H.; Neulinger, S.C.; Heinsen, F.A.; Knecht, C.; Schilhabel, A.; Schmitz-Streit, R.A.; Zimmermann, A.; Dos Santos, V.M.; Ferrer, M.; Rosenstiel, P.; et al. Effects of $\beta$-lactam antibiotics and fluoroquinolones on human gut microbiota in relation to Clostridium difficile associated diarrhea. PLoS ONE 2014, 9, e89417. [CrossRef] [PubMed]

23. Pawłowska, I.; Ziółkowski, G.; Wójkowska-Mach, J.; Bielecki, T. Can surgical site infections be controlled through microbiological surveillance? A three-year laboratory-based surveillance at an orthopaedic unit, retrospective observatory study. Int. Orthop. 2019, 43, 2009. [CrossRef]

24. European Centre for Disease Prevention and Control. Healthcare-associated infections: Surgical site infections. In Annual Epidemiological Report for 2015; ECDC: Stockholm, Sweden, 2017.

25. Bovonratwet, P.; Bohl, D.D.; Malpani, R.; Nam, D.; Della Valle, C.J.; Grauer, J.N. Incidence, Risk Factors, and Impact of Clostridium Difficile Colitis Following Primary Total Hip and Knee Arthroplasty. J. Arthroplasty. 2018, 33, 205-210. [CrossRef]

26. Howell, M.D.; Novack, V.; Grgurich, P.; Soulliard, D.; Novack, L.; Pencina, M.; Talmor, D. Iatrogenic gastric acid suppression and the risk of nosocomial Clostridium difficile infection. Arch. Intern. Med. 2010, 170, 784-790. [CrossRef]

27. Janarthanan, S.; Ditah, I.; Adler, D.; Ehrinpreis, M.N. Clostridium difficile-associated diarrhea and proton pump inhibitor therapy: A meta-analysis. Am. J. Gastroenterol. 2012, 107, 1001-1010. [CrossRef] [PubMed]

28. Su, T.; Lai, S.; Lee, A.; He, X.; Chen, S. Meta-analysis: Proton pump inhibitors moderately increase the risk of small intestinal bacterial overgrowth. J. Gastroenterol. 2018, 53, 27-36. [CrossRef] 
29. Furuya-Kanamori, L.; Stone, J.C.; Clark, J.; McKenzie, S.J.; Yakob, L.; Paterson, D.; Riley, T.V.; Doi, S.; Clements, A.C. Comorbidities, exposure to medications, and the risk of community-acquired Clostridium difficile infection: A systematic review and metaanalysis. Infect. Control Hosp. Epidemiol. 2015, 36, 132-141. [CrossRef]

30. Wojkowska-Mach, J.; Godman, B.; Glassman, A.; Kurdi, A.; Pilc, A.; Rozanska, A.; Skoczyński, S.; Wałaszek, M.; Bochenek, T. Antibiotic consumption and antimicrobial resistance in Poland; findings and implications. Antimicrob. Resist. Infect. Control 2018, 7, 136. [CrossRef]

31. Wojkowska-Mach, J.; Brudło, M.; Topolski, M.; Bochenek, T.; Jachowicz, E.; Siewierska, M.; Różańska, A. Antibiotic consumption in long-term care facilities in Poland and other European countries in 2017. Antimicrob. Resist. Infect. Control. 2021, 10, 154. [CrossRef] [PubMed]

32. EMA. European Medicines Agency: Quinolone- and Fluoroquinolone-Containing Medicinal Products; EMA: Amsterdam, The Netherlands, 2019. Available online: https://www.ema.europa.eu/en/medicines/human/referrals/quinolone-fluoroquinolonecontaining-medicinal-products (accessed on 1 October 2021). 